\title{
Seasonal Distribution of Diarrhea among Children aged 1-5 Years in Slums of Southern India: A Cross-Sectional Door to Door Survey
}

INTRODUCTION: Diarrhea, a water borne disease is very prevalent in children under 5 years of age and lead to serious consequences among them if not treated on time.

AIM: To assess the Seasonal Distribution of diarrhea among children aged 1-5 years in slums of southern India

MATERIALS AND METHOD: The study was a planned door to door survey via a standard, pre-validated and pre-tested questionnaire among the slums the states of Maharashtra, Karnataka, Tamil Nadu and Kerala. Data was collected from the mothers/caretakers of children aged 1-5 years regarding Diarrheal episodes in the past one year. Data was analysed using SPSS version 22.0 and by applying the independent samples t-test as well as the multivariate logistic regression.

RESULTS: A total of 2684 children were reported having diarrhea, out of which there were slightly more females $(52.1 \%)$ as compared to males (47.9\%). $55.1 \%$ of children were treated at home, while $34.2 \%$ needed consultation and $10.7 \%$ required hospitalization. Most cases were reported in the monsoon season $(39.3 \%)$, followed by summer $(30.6 \%)$, winter $(22.5 \%)$ and autumn $(7.6 \%)$. The independent samples t-test $(\mathrm{p}=0.03)$ as well as the multivariate logistic regression $(\mathrm{p}=0.01)$ showed significant results while comparing the occurrence of diarrhea in monsoon seasons in comparison to other seasons.

CONCLUSION: Further studies are advised among slum dwellers so that proper and tailor made programs can be directed in reducing the effect of diarrhea in children residing in slums in southern India.

KEYWORDS: Diarrhea, Children, Mortality, Summer

\section{INTRODUCTION}

Among children in developing countries, diarrheal diseases have been attributed as a major cause of morbidity and mortality. ${ }^{1,2}$ Across the globe, it has been reported that children under five years experience an average of 3.2 diarrheal episodes per year with and estimated death of 1.87 million children as a result of dehydration due to diarhea. ${ }^{3,4}$

According to $\mathrm{WHO}$, diarrhea is the passage of 3 or more times loose or liquid stools per day or more frequently than the normal for the individual is classified as diarrhea. Among children, diarrhea can also lead to malnutrition, stunted growth and reduced well-being; as a result of which, can affect intellectual development, leading to significantly lower than average scores in intelligence tests. The diarrhoeic episodes also need medical attention leading to increased costs of care, especially among the economically weak societies.

The prevalence of diarrhea varies as per seasons; It has been reported that in temperate climates, bacterial diarrhea occur more frequently during the warm season, whereas viral diarrhea, particularly diarrhea caused by rotavirus peak during the winter. The incidence of rotavirus diarrhea is seen throughout the year in tropical climates with an increased incidence in drier, cool months. Authors report that persistent diarrhea follows the same seasonal patterns as that of acute watery Diarrhea. ${ }^{5-7}$

A study carried out 2013 revealed six factors independently associated with diarrheal diseases which were consisted of occupation of the parent/guardian, not washing hands after changing napkins by the caregiver/guardian, the child drinking untreated water, child not exclusively breastfed and the child not washing hands before going to the washroom and eating one's food. ${ }^{8}$

Due to the above mentioned factors regarding diarrhea and its ability to cause mortality/serious effects on children and its relation with seasonal variations, the present study was carried out to assess

(C) Sreekant P. et al. This is an open access article distributed under the terms of the Creative Commons Attribution License CC-BY-NC 4.o, which permits unrestricted use, distribution and reproduction in any medium, provided the use is not commercial and the original author(s) and source are cited. 
the seasonal distribution of diarrhea among children aged 1-5 years in Slums of southern India.

\section{MATERIALS AND METHODS}

The present study was planned as a door -to door survey among various slums in southern India, which comprised of the states of Maharashtra, Karnataka, Tamil Nadu and Kerala from $1^{\text {st }}$ December 2018 to $1^{\text {st }}$ July, 2019. Data collection was done via a standard, prevalidated and pre-tested questionnaire with Cronbach's alpha as 0.7.

Prior to the commencement of the study, all necessary approvals were obtained and a written, informed consent was taken from the participants. Participants included mothers, fathers or caretakers of children aged 1-5 years and they were asked about data occurrence of diarrhea among the children in the past one year.

The questionnaire was filled by volunteers recruited prior to the study and duly standardized to the study objectives as well as the data required to be filled in the questionnaire. An important criteria was that the volunteers, needed to speak the local language to avoid any comprehension/language bias by the participants. Based on the results of a pilot study, the minimum sample required was 354. However, inclusion of massive sample was sought by the researchers. Data was analysed using SPSS version $\mathbf{2 2 . 0}$ and by applying the independent samples $t$-test as well as the multivariate logistic regression.

\section{RESULTS}

Table 1 describes the study population. A total of 2684 children were reported having diarrhea, out of which there were slightly more females (52.1\%) as compared to males $(47.9 \%)$.

\begin{tabular}{|c|c|}
\hline GENDER & AGED 1-5 YEARS \\
\hline Males & $1399(47.9 \%)$ \\
\hline Females & $1285(52.1 \%)$ \\
\hline Total & $2684(100 \%)$ \\
\hline
\end{tabular}

Table 1. Characteristics of the Study Population

The treatment modality adopted for diarrhea is shown in table 2. It was observed that $55.1 \%$ of children were treated at home, while $34.2 \%$ needed consultation from a doctor and only $10.7 \%$ of children required hospitalization.

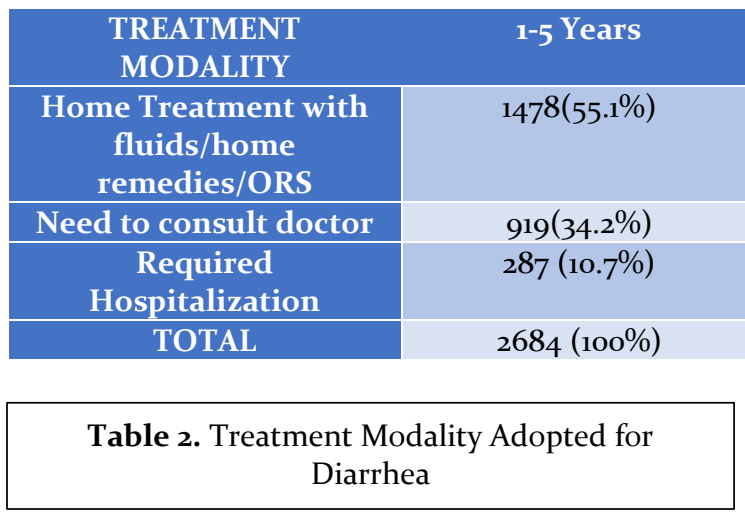

The seasonal occurrence of diarrhea is shown in table 3. Most cases were reported in the monsoon season (39.3\%), followed by summer (30.6\%), winter(22.5\%) and autumn $(7.6 \%)$. The independent samples t-test $(\mathrm{p}=\mathrm{0.03})$ as well as the multivariate logistic regression ( $\mathrm{p}=\mathrm{o.01}$ ) showed significant results while comparing the occurrence of diarrhea in monsoon seasons in comparison to other seasons (table 3).

\begin{tabular}{|c|c|c|c|}
\hline SEASON & 1-5 Years & $\begin{array}{c}\mathbf{P} \\
\text { value }\end{array}$ & $\begin{array}{c}\text { Multivariate } \\
\text { Analysis }\end{array}$ \\
\hline Monsoon & $\begin{array}{c}1054 \\
(39 \cdot 3 \%)\end{array}$ & \multirow{5}{*}{$0.03^{*}$} & \multirow{5}{*}{$0.01^{*}$} \\
\hline Summer & $\begin{array}{c}822 \\
(30.6 \%)\end{array}$ & & \\
\hline Winter & $\begin{array}{c}604 \\
(22.5 \%)\end{array}$ & & \\
\hline Autumn & $204(7.6 \%)$ & & \\
\hline TOTAL & $\begin{array}{c}2684 \\
(100 \%)\end{array}$ & & \\
\hline
\end{tabular}

Table 3. Frequency Of Diarrhea Occurrence As Per Seasons

\section{DISCUSSION}

Across the globe, acute Diarrheal outbreaks have been commonly attributed to contaminated water worldwide. 9 The present study revealed that most cases of diarrhea most cases were treated at home with home remedies/fluids (55.1\%) and is lower as compared to 90.6\% (Sutariya et al.) ${ }^{10}$ Bhattacharya $\mathrm{R}$ et al. reported that Camphor and Asfoetida were the commonly used home remedies followed by salt sugar solution of variable composition, soda water with sugar and lemon. ${ }^{11}$

It was observed that most cases of diarrhea in children occurred in the monsoon season (39.3\%). These results are contraindicated by studies of Jayalakshmy $R$ et al. 
and Gupta N et al. who reported the maximum incidence of diarrheal diseases during the summer months followed by rainy or winter months. ${ }^{12,13}$

It has been reported that the risk of developing diarrheal diseases was 6.41 times higher among undernourished children compared with normal children. ${ }^{14}$ Authors have also reported that socioeconomic status, poor maternal literacy, inadequate breastfeeding, malnutrition, poor sanitation and hygiene practices of the mother are associated with a higher incidence of diarrheal diseases in young children. ${ }^{15}$

Due to the exploratory nature of the present study, the results post a grim picture of diarrhea among children under age 5 in slums of southern India. The limitations of the present study includes social desirability bias and recall bias by the respondents. However, we results of the present study can be generalized for the population and further studies are advised among slum dwellers so that proper and tailor made programs can be directed in reducing the effect of diarrhea in children residing in slums in southern India.

\section{CONCLUSION}

Based on the results of the present study, further, detailed studies are advised, as well as targeted educational programmes to educate the children and their mothers regarding their general health (hand washing) and proper food processing etc.

\section{REFERENCES}

1. Bin Mohanna MA, Al-Sonboli N. Prevalence of Diarrhea and related risk factors among children aged under 5 years in Sana'a, Yemen. Hamdan Med J. 2018;11:29-33

2. Kahlownn M, Tahir M, Rasheed H, Bhatti K. National water quality monitoring programme. Tech Rep. Fourth Technical Report, Pakistan Council of Research in water Resources, 2006.

3. Kosek M, Bern C, Guerrant RL. The global burden of Diarrheal disease, as estimated from studies published between 1992 and 2000. Bulletin of the World Health Organization 2003;81(3):197-204.

4. Boschi-Pinto C, Velebit L, Shibuya K. Estimating child mortality due to Diarrhea in developing countries. Bulletin of the World Health Organization 2008; 86(9):710-7.

5. Bowen A, Agboatwalla M, Luby S, Tobery T, Ayers T, Hoekstra RM, et al. Association between intensive handwashing promotion and child development in Karachi, Pakistan: A cluster randomized controlled trial. Arch Pediatr Adolesc Med. 2012;166:1037-44.

6. Grantham-McGregor SM, Walker SP, Chang S. Nutritional deficiencies and later behavioural development. Proc Nutr Soc. 2000;59:47-54.

7. Ahmed SF, Farheen A, Muzaffar A, Mattoo GM. Prevalence of Diarrheal Disease, its Seasonal and Age Variation in under- fives in Kashmir, India. Int J Health Sci (Qassim). 2008;2(2): 126-133.

8. Karambu S, Matiru V, Kiptoo M, Oundo J, Characterization and factors associated with Diarrheal diseases caused by enteric bacterial pathogens among children aged five years and below attending Igembe District Hospital, Kenya. The Pan African Medical Journal 2014; 16(1):37.

9. WHO. Global Water Supply and Sanitation Assessment 2000 Report. Geneva: World Health Organization, 2000.

10. Sutariya S, Talsania N, Shah C. Study Of Prevalence Of Diarrheal Diseases Amongst Under Five Population. National Journal Of Community Medicine 2011; 2(1):9699.

11. Bhattacharya R, Kaur P. Epidemiology Correlates Of Diarrhea In A Rural Area Of Varanasi. Indian Journal of Community Medicine 1989; 14(2):79-82.

12. Jayalakshmy R, Roy G, Premarajan KC. Incidence and risk factors of acute diarrheal disease among under-five children in urban slums in Pondicherry zOne year follow-up study. Indian J Matern Child Health. 2011;13:1-11

13. Gupta N, Jain SK, Ratnesh, Chawla U, Hossain S, Venkatesh S. An evaluation of diarrheal diseases and acute respiratory infections control programmes in a Delhi slum. Indian J Pediatr. 2007;74:471-6.

14. Melese B, Paulos W, Astawesegn FH, et al. Prevalence of diarrheal diseases and associated factors among under-five children in Dale District, Sidama zone, Southern Ethiopia: a cross-sectional study. BMC Public Health 19, $1235 \quad$ (2019). https://doi.org/10.1186/s12889-019-7579-2.

15. Singh J, Gowriswari D, Chavan B, Patiat R, Debnath A, Jain D, et al. Diarrheal diseases amongst children under five. A study in rural Alwar. J Commun Dis. 1992;24(3):150-5. 
Cite this article as:

Sreekant P., Jayapraksh T., Iyenger P. Seasonal Distribution of Diarrhea among Children aged 1-5 Years in Slums of Southern India: A Cross-Sectional Door to

Door Survey. Int Healthc Res J. 2020;4(6):158-161.

https://doi.org/10.26440/IHRJ/0406.09185

AUTHOR AFFILIATIONS: ( ${ }^{*}$ Corresponding Author)

1. MD (Internal Medicine), Consultant Private Practitioners, Hyderabad, India.

Source of support: Nil, Conflict of interest: None declared

Contact Corresponding Author at: noicares[at]outlook[dot]com 